\title{
Human placental extract: a potential therapeutic in treating osteoarthritis
}

\author{
Chukwuweike Gwam ${ }^{1}$, Chiemena Ohanele ${ }^{2}$, Jacob Hamby ${ }^{1}$, Noor Chughtai ${ }^{3}$, Zarmina Mufti $^{4}, \mathrm{Xue} \mathrm{Ma}^{1}$ \\ ${ }^{1}$ Department of Orthopedic Surgery, Wake Forest School of Medicine, Winston-Salem, NC, USA; ${ }^{2}$ Howard University College of Pharmacy, \\ Washington, DC, USA; ${ }^{3}$ Virginia Commonwealth University, Richmond, VA, USA; ${ }^{4}$ Frontier Medical College, Abbottabad, Pakistan \\ Contributions: (I) Conception and design: C Gwam, C Ohanele, X Ma; (II) Administrative support: All authors; (III) Provision of study materials \\ or patients: All authors; (IV) Collection and assembly of data: C Gwam, C Ohanele, J Hamby; (V) Data analysis and interpretation: C Gwam, C \\ Ohanele, J Hamby, X Ma; (VI) Manuscript writing: All authors; (VII) Final approval of manuscript: All authors. \\ Correspondence to: Chukwuweike Gwam. Department of Orthopedic Surgery, Wake Forest School of Medicine, Winston-Salem, NC, USA. \\ Email: cgwam1988@gmail.com.
}

\begin{abstract}
Osteoarthritis (OA) is a degenerative joint disease marked by cartilage degradation and loss of function. Recently, there have been increased efforts to attenuate and reverse OA by stimulating cartilage regeneration and preventing cartilage degradation. Human placental extract (HPE) may be an option due to its anti-inflammatory, antioxidant, and growth stimulatory properties. These properties are useful in preventing cell death and senescence, which may optimize in-situ cartilage regeneration. In this review, we discuss the anatomy and physiology of the placenta, as well as explore in vivo and in vitro studies assessing its effects on tissue regeneration. Finally, we assess the potential role of HPE in cartilage regenerative medicine and OA. The Medline database was utilized for all studies that involved the use of HPE or human placenta hydrolysate. Exclusion criteria included articles not written in English, conference reviews, editorials, letters to the editor, surveys, case reports, and case series. HPE had significant anti-inflammatory and regenerative properties in vitro and in vivo. Furthermore, HPE had a role in attenuating cellular senescence and cell apoptosis via reduction of reactive oxidative species both in vitro and in vivo. One study explored the effects of HPE in OA and demonstrated reduction in cartilage catabolic gene expression, indicating HPE's effect in attenuating OA. HPE houses favorable properties that can attenuate and reverse tissue damage. This may be a beneficial therapeutic in $\mathrm{OA}$ as it creates a more favorable environment for in-situ cartilage regeneration. More well designed in-vitro and in-vivo studies are needed to define the role of HPE in treating OA.
\end{abstract}

Keywords: Placental extract; osteoarthritis (OA); therapy; in vitro; in vivo

Submitted Sep 11, 2019. Accepted for publication Sep 29, 2019.

doi: $10.21037 /$ atm.2019.10.20

View this article at: http://dx.doi.org/10.21037/atm.2019.10.20

\section{Introduction}

Osteoarthritis $(\mathrm{OA})$ is one the most prevalent musculoskeletal maladies with a global age-adjusted prevalence of $25.4 \%$ and $19.6 \%$ for knee and hip OA respectively (1). It is associated with significant disability and costs, as it ranks $11^{\text {th }}$ in disability adjusted life years lost and costs over 300 billion dollars annually in the United States (2). Of this, wages lost due to symptomatic OA comprises the major portion of the burden imposed on the economy (3). As such, preventing and treating $\mathrm{OA}$ is essential for optimizing population health and world economies. The pathology of OA can be characterized radiographically by progressive cartilage degeneration, formation of subchondral bone cysts, reactionary osteophyte formation, and end-stage joint space narrowing and collapse. Yet, there is discordance between symptomatic and radiographic $\mathrm{OA}$ as symptoms often do not correlate with radiographic severity (4). As such, treatment is centered on symptom severity.

Historically, OA has been described as a disease of "wear-and-tear" characterized by joint degeneration. OA 
was thought to be irreversible due to the poor healing capability of articular cartilage. The limited healing capacity of articular cartilage was largely attributed to its poor vascularity and low cell turnover (5). However, increasing insight unto the cellular processes of $\mathrm{OA}$ has created a clearer picture. A growing body of evidence now suggests the poor regenerative capability of cartilage regeneration to be due to chondrocyte senescence (6-9) and apoptosis that occurs during chronic inflammation. This phenomenon tips the balance of normal homeostatic processes that occur in the joint towards a catabolic state (10).

Conventional treatment options focus on joint stabilization and symptom relief. These treatment modalities include rest, ice, physical therapy, and nonsteroidal anti-inflammatory drugs (NSAIDs) for mild $\mathrm{OA}$ to intra-articular steroid injection and eventual joint replacement for severely symptomatic OA. Unfortunately, these modalities function to diminish symptoms and do little to regenerate joint tissue damage. Newer insight stemmed from advances in the biological sciences suggest potential for cartilage regeneration and a reversal of OA (11). This is now the target of newer modalities such as platelet rich plasma (PRP), amnion derived stem cells (AMSCs), and mesenchymal stem cell (MSC) therapy, which focus on regenerating articular cartilage and reversing $\mathrm{OA}$ progression.

PRP is a supra-physiological filtrate of platelet and cytokines, derived from patient plasma, that functions to catalyze anabolic processes in the joint. AMSCs utilize pluripotent cells from human amnion to stimulate chondrocyte differentiation in order to regenerate articular cartilage. Similarly, autologous MSCs differentiate along the chondrogenic pathway in order to stimulate cartilage repair (12). Despite a plethora of in-vitro studies supporting the use of PRPs (13), AMSCs, and MSCs, the regenerative potential of these therapies has not been demonstrated in humans. Varying explanations exists for the lack of results with the use of these modalities. PRP, while effective in vitro, experiences a significant drop in efficacy once injected in a joint. This has been attributed to a highly variable quality of derived platelets (14), platelet inactivation, and external patient factors such as the use of NSAIDs (15). Stem cell therapy has not yet demonstrated regenerative capability of articular cartilage in human studies and may be proinflammatory. This is because of senescent chondrocyte (snCho) activity, which are found accumulated in OA, that acts to suppress exogeneous stem cells (16).

Human placental extract (HPE; also known as human placenta hydrolysate) is a potential treatment option for attenuating and reversing OA progression. The formulation is derived from a post-delivery placenta that subsequently undergoes cellular hydrolysis. The resulting extract houses high levels of growth factors, anabolic cytokines, nucleic acids, and essential amino acids that may stimulate tissue regeneration and anti-inflammatory proteins that attenuate inflammation. HPE has a strong history in oriental regions and has shown to be effective in a myriad of pathologies. In this review, we covered the anatomy and physiology of the placenta, its immunomodulatory properties, and the formulation and rationale behind HPE use. We also explored in-vitro and in-vivo studies to uncover the properties and efficacy of HPE as a treatment modality. Finally, we assessed the potential role of HPE in cartilage regenerative medicine and $\mathrm{OA}$.

\section{Methods}

An electronic systematic review of the literature was conducted using the Medline database. Studies published in the field were identified using various keyword combinations and Boolean operators. The search was performed in April 2019. The following strings were used for the search:

"Placental Extracts"[Majr], "Placental Extracts/ therapeutic use"[Mesh], "Placental Extracts"[Mesh], OR "placenta extract"/exp OR "placenta extract", "Placental Extracts/therapeutic use"[Mesh] AND "osteoarthritis"[Mesh], ("humans"[MeSH Terms] OR "humans"[All Fields] OR "human"[All Fields]) AND ("placenta"[MeSH Terms] OR "placenta"[All Fields]) AND hydrolysate[All Fields]

The exclusion criteria were as follows: articles not written in English, conference reviews, editorials, letters to the editor, surveys, case reports, and case series.

\section{Results}

\section{The placenta}

\section{Structure}

The placenta is a temporary organ that ensures the coexistence of a developing fetus and the maternal body. It functions to maintain blood supply to the fetus as well as the removal of metabolic waste and preventing immune rejection $(17,18)$. The post-delivery placenta is typically 16 to $20 \mathrm{~cm}$ in diameter and on average weighs $500 \mathrm{~g}$. It 
can be divided into the fetal placenta which is developed from blastocysts, and the maternal placenta, which develops from maternal uterine tissue. The fetal part of the placenta includes the amnion, umbilical cord and the chorionic plate. The chorionic plate is comprised of fibroblasts and trophoblasts which functions to provide structure and nutrients to the placenta. The amnion contains pluripotent stem cells that are involved in the development of the fetus. Finally, the umbilical cord is involved in providing nutrients and blood as well as waste removal for the fetus. In it contains two arteries and one vein all immersed in fluid rich with hyaluronic acid and fibroblast cells.

\section{Immunomodulatory properties}

The placenta protects the developing fetus from the maternal immune system thus serving as a model for an insitu organ allograft (19). In doing so, the placenta plays a critical immunomodulatory role in order to prepare and maintain an environment conducive to fetal development. Integral to this role is stem cell [placental mesenchymal stem cells (pMSCs)] activity on the maternal immune system. pMSCs express the membrane bound human leukocyte antigen (HLA)-G which is known to inhibit T cell function and proliferation (20-22). Specifically, pMSCs prevent proliferation and release of cytokines by $\mathrm{T}$ helper-1 (Th1) cells while inducing the expression and secretion of $\mathrm{T}$ helper-2 (Th2) cytokines (23). Furthermore, pMSCs induce the differentiation of $\mathrm{T}$ regulatory lymphocytes, $\mathrm{Th} 2$ polarization (associated with increased levels of IL-4 and IL-10), and Th17 induction (produce high concentrations of IL-6 and IL-7). This is achieved through direct pMSC contact with $\mathrm{T}$ cells and the secretion of soluble cytokines and anti-inflammatory mediators (24) which serve to attenuate $T$ cell activity. This same anti-inflammatory effect has been observed on other cell types including B cells (25), macrophages (26), and dendritic cells (27). pMSCs have been explored clinically in patients with knee arthritis. In their pilot study, Soltani et al. revealed intra-articular injection of pMSCs is safe and provided pain improvement for patients with OA, suggesting that single or multiple injections may improve and prolong the efficacy of MSC therapy (28).

\section{Rationale for the use of acellular placenta preparation}

Despite pMSCs immunomodulatory processes, its use in an osteoarthritic joint has not been demonstrated to be effective, with some studies suggesting worsening of OA. This may be due to early onset inactivation by snChos found accumulated in an osteoarthritic joint. This inhibitory effect on transplanted stem cells by snChos was demonstrated in a study conducted by Cao et al. (16). The authors reported snChos-mediated-apoptosis of bone marrow-derived mesenchymal stem cells (BMSCs) after 21 days of co-culture that was reduced after the administration of ABT-263 (an antisenescence agent) (29). Furthermore, the authors reported promotion of BMSC senescence by native snChos. This apoptotic and senescent effect was bidirectional, as the implanted BMSCs increased the rate of apoptosis and senescence of healthy chondrocytes, in addition to stimulating an increased expression of IL-6, IL-1b, matrix metalloproteinase (MMP)-1, and MMP-13. Another study conducted by Endrinaldi et al. (30) revealed increased levels of IL-4 and MMP-1 after injection of pMSCs in osteoarthritic rat knees suggesting increased degradation of cartilage extracellular matrix after pMSC administration.

\section{Nutrient content and properties of placental extract}

The placenta is capable of retaining nutrients and growth factors necessary after delivery (31). Placenta extract is formulated by the hydrolyzation of placental cells. The resulting extract contains collagen, elastin, laminin, vitamins, trace elements, nucleic acids, amino acids, peptides, cytokines and growth factors (32-35). Polydeoxyribonucleotide (PRDN), an active component, composed of different lengths of deoxyribonucleotide polymers extracted from the placenta, activates the salvage pathway for biosynthesis of nucleosides, nucleotides, and nucleic acids $(32,36)$. It has shown efficacy in augmenting healing for scars, ulcers, and wounds $(35,37,38)$. Similarly, placental extract contains supraphysiologic levels of essential and non-essential amino acids such as alanine, aspartic acid, histidine, arginine, phenylalanine, proline, tryptophan, lysine, tyrosine, leucine, and valine (32,39-41). This has been shown to stimulate fibroblast proliferation and collagen production in vitro (41). Vitamins $B_{1}, B_{2}$, $\mathrm{B}_{5}, \mathrm{~B}_{6}, \mathrm{~B}_{7}, \mathrm{~B}_{9}$, and $\mathrm{B}_{12}$ are found in high concentrations in HPE formulation and play a role in cell metabolism and energy protection (42). Furthermore, studies have demonstrated a high concentrate of cytokines and growth factors housed by the post-delivery placenta. These factors include granulocyte colony-stimulating factor (G-SCF), granulocyte-macrophage colony-stimulating factor (GMCSF), epidermal growth factor (EGF), fibroblast growth factor (FGF), hepatocyte growth factor (HGF), insulin growth factor (IGF), platelet-derived growth factor (PDGF), transforming growth factor (TGF), and vascular endothelial 
Table 1 Summary of studies exploring the anti-inflammatory properties of HPE

\begin{tabular}{|c|c|c|}
\hline Author and year & Experiment & Results \\
\hline $\begin{array}{l}\text { Yamauchi et al. } \\
2017 \text { (48) }\end{array}$ & $\begin{array}{l}\text { HPE in preventing non-alcoholic steatohepatitis in } \\
\text { wild-type C57BL/6J mice }\end{array}$ & $\begin{array}{l}\text { Less fibrosis, decrease in TNF-alpha, decrease in MMP-9, and } \\
\text { less oxidative stress in the perivascular hepatic regions }\end{array}$ \\
\hline $\begin{array}{l}\text { Samiei et al. } 2016 \\
\text { (49) }\end{array}$ & $\begin{array}{l}\text { HPE in preventing amiodarone induced pulmonary } \\
\text { fibrosis in Sprague-Dawley rats }\end{array}$ & $\begin{array}{l}28 \% \text { percent reduction in alveolar septum thickness and less } \\
\text { lung inflammation in groups treated with HPE }\end{array}$ \\
\hline
\end{tabular}

HPE, human placental extract; B[a]P, Benzo(alpha)Pyrene; MMP, matrix metalloproteinase.

growth factor (VEGF), all of which have demonstrated antiinflammatory and regenerative properties (43-46).

\section{HPE in attenuating inflammation and facilitating tissue regeneration}

HPE has shown significant promise as a therapeutic through its anti-inflammatory and anti-oxidant properties. The following studies explore the effect of HPE on mitigating organ inflammation and facilitating recovery (see Table 1).

\section{HPE in the reduction of tissue and organ damage}

Parida et al. explored the role of HPE in mitigating the effects of Benzo(alpha)Pyrene $\{\mathrm{B}[\mathrm{a}] \mathrm{P}\}$ in the hippocampi of Wistar rat pups (47). $\mathrm{B}[\mathrm{a}] \mathrm{P}$ is a procarcinogen that is known to lead to neuronal damage via cytochrome P450 1A1 (CYP1A1)-mediated metabolism. In their study, the authors created two sets of experiments. The first set contained five experimental groups: normal control, vehicle control \{buffer without $\mathrm{B}[\mathrm{a}] \mathrm{P}\}, 0.25 \mu \mathrm{M} \mathrm{B}[\mathrm{a}] \mathrm{P}, 0.5 \mu \mathrm{M} \mathrm{B}[\mathrm{a}] \mathrm{P}$; and $1.0 \mu \mathrm{M}$ $\mathrm{B}[\mathrm{a}] \mathrm{P}$. The second set contained four experimental groups: (I) a normal control; (II) minimal $\mathrm{B}$ [a]P concentration inducing inflammation; (III) HPE injection and; (IV) HPE injection followed by B[a]P treatment; (V) HPE followed by $0.25 \mu \mathrm{M} B[\mathrm{a}] \mathrm{P}$. The authors reported lower levels of the inflammatory marker NF- $\mathrm{NB}$ in groups treated with $\mathrm{HPE}$ followed by $0.25 \mu \mathrm{MB}$ [a]P when compared to $\mathrm{B}[\mathrm{a}] \mathrm{P}$ alone, and lower levels of both TNF-alpha and IL-2 in HPE treated group when compared to the $0.25 \mu \mathrm{M} \mathrm{B}[\mathrm{a}] \mathrm{P}$ treated group.

Yamauchi et al. (48) explored the role of HPE on the prevention of non-alcoholic steatohepatitis (NASH) in wild-type $\mathrm{C} 57 \mathrm{BL} / 6 \mathrm{~J}$ mice by utilizing a NASH-mouse model. The authors demonstrated less pronounced fibrosis and a decrease in TNF-alpha and MMP-9 expression in the HPE-treated mice. Additionally, the authors revealed lower levels of oxidative stress in the perivascular hepatic regions. Samiei et al. (49) assessed the role of HPE in preventing amiodarone induced pulmonary fibrosis in male SpragueDawley rats. Amiodarone is an antiarrhythmic therapeutic that has been implicated in multiple side effects such as pulmonary, ocular, thyroidal, and liver toxicity due to its formation of reactive oxygen species once metabolized $(50,51)$. In their study, the first, second, and third groups received no treatment, amiodarone $(100 \mathrm{mg} / \mathrm{kg})$, and HPE (500 $\mu \mathrm{L} / \mathrm{kg}$; intraperitoneal injection), respectively. The fourth group was treated with amiodarone + HPE. The authors reported a decrease in total alveolar space in the amiodarone group that was not observed in the amiodarone + HPE group. Furthermore, there was $28 \%$ increase in alveolar septum thickness in the amiodarone group that was not observed in the amiodarone + HPE group. Finally, the authors reported a reduction in inflammation in the amiodarone + HPE group when compared to the amiodarone group.

\section{HPE as an anti-apoptotic, promoting cell proliferation} and tissue regeneration

Studies exist that highlight the proliferative and regenerative potential of HPE on organ cells (see Table 2). HPE contains supraphysiologic levels of anabolic factors that promote cellular proliferation that allows for tissue regeneration.

Kwon et al. (52) explored the role of HPE in preventing hair loss through its effects on the $\mathrm{Wnt} / \beta$-catenin signaling pathway. The authors revealed that HPE mediated induction of $\beta$-catenin expression through the inhibition of glycogen synthase kinase $3 \beta$ as well as induction of alkaline phosphatase expression in human dermal papilla cells. The authors also demonstrated that HPE was effective in inducing root hair elongation in rat vibrissa hair follicles. Hong et al. (53) explored the role of HPE in a wound healing mouse model. The authors reported accelerated 
Table 2 Studies exploring the anti-apoptotic and tissue regenerative properties of HPE

\begin{tabular}{lll}
\hline Author and year & Experiment & Results \\
\hline Kwon et al. 2015 (52) & $\begin{array}{l}\text { HPE in preventing hair loss through the Wnt/ } \\
\beta \text {-catenin signaling pathway }\end{array}$ & $\begin{array}{l}\text { Induction of } \beta \text {-catenin expression as well as induction of alkaline } \\
\text { phosphatase in human dermal papilla cells }\end{array}$ \\
Hong et al. 2010 (53) & Role in HPE in a wound healing mouse model & $\begin{array}{l}\text { Accelerated wound healing among mice treated with HPE. Higher } \\
\text { levels of TGF- } \beta \text { and VEGF among mice treated with HPE }\end{array}$ \\
\hline
\end{tabular}

HPE, human placental extract; VEGF, vascular endothelial growth factor.

Table $3 \mathrm{HPE}$ and its effect on reactive oxygen species

\begin{tabular}{lll}
\hline Author and year & Experiment & Results \\
\hline Lee et al. 2011 (62) & HPE's role on liver regeneration in Sprague-Dawley rats & Upregulation of cellular antioxidants \\
Bak et al. 2018 (63) & $\begin{array}{l}\text { HPE's role in preventing D-galactosamine induced liver } \\
\text { toxicity }\end{array}$ & $\begin{array}{l}\text { Induction of antioxidant enzymes and a reduction in } \\
\text { reactive oxygen species }\end{array}$ \\
Bak et al. 2019 (64) & $\begin{array}{l}\text { HPE's role in preventing hydrogen peroxide induced cell } \\
\text { death in C2C12 mouse myoblasts }\end{array}$ & $\begin{array}{l}\text { Reduction of cytosolic and mitochondrial ROS through } \\
\text { NF-кB signaling }\end{array}$ \\
\hline
\end{tabular}

HPE, human placental extract; ROS, reactive oxygen species.

wound healing in the experimental group (received HPE treatment) compared to the control group. Additionally, the authors demonstrated a higher quantity of TGF- $\beta$ and VEGF after wound analysis in the experiment group when compared to control.

\section{HPE and reduction of reactive oxygen species}

Reactive oxidation species (ROS) causes damage to cellular DNA which elicits irreversible growth arrest and apoptosis $(54,55)$. Stress-induced premature senescence (SIPS) is cellular phenotype often induced by ROS and is characterized as an arrest of cellular replication and increased cellular release of inflammatory factors $(7,56)$. Cellular mitochondria serve as the main source of ROS and is increased during surges in cellular metabolism $(57,58)$. Enzymes, such as glutathione reductase (59), catalase (60), and superoxide dismutase (61) serve as cellular defenses against ROS. Studies exist demonstrating HPE's capability in reducing intracellular ROS (see Table 3) thereby preventing SIPS and premature cellular apoptosis.

Lee et al. (62) explored the role of HPE on hepatocyte proliferation and liver regeneration in Sprague-Dawley rats. They reported HPE to have significant radical scavenging activity and lipid peroxidation inhibitory effect in a dose dependent manner. Additionally, Lee and colleagues reported increased proliferation of hepatocytes and accelerated liver regeneration after partial hepatectomy in the experimental group (+ HPE). The authors also demonstrated a higher quantity of mitotically active cells (ki-67 positive) in the experimental group and an increase in glutathione peroxidase and superoxide dismutase, thereby suggesting evidence of less oxidative stress. Bak et al. (63) reported on the anti-apoptotic effects of HPE against hepatocyte toxicity in vivo and in vitro. Their study involved the use D-galactosamine (D-GalN)- and lipopolysaccharide (LPS)-induced hepatocyte apoptosis in vivo and in vitro. The treatment was defined as $\mathrm{HPE}$ administration. The authors found that pre-treatment with HPE led to improved cell viability, reduction in apoptosis protein expression, increase in proliferating cell nuclear antigen (PCEN), and induction of antioxidant enzymes such as superoxide dismutase, glutathione peroxidase, and catalase. Furthermore, the authors reported HPE mediated reduction in reactive oxygen species and the reduction of damage-regulated autophagy modulator, $\mathrm{p} 53$, and C/EBP homologous protein. In a separate study, Bak et al. (64). demonstrated the antioxidant effect of HPE against oxidative stress on muscle atrophy. The authors reported HPE inhibition of hydrogen peroxide induced cell death in $\mathrm{C} 2 \mathrm{C} 12$ cells, and reduction of cytosolic and mitochondrial ROS through myostatin gene expression via NF- $\mathrm{KB}$ signaling.

In conclusion, multiple studies demonstrate HPE's effectiveness in reducing inflammation, preventing cell damage and optimizing cell viability. The most critical aspect of HPE may be its ability to reduce oxidative stress 
Table 4 Study explaining the therapeutic effects of HPE in osteoarthritis

\begin{tabular}{lll}
\hline Author and year & Experiment & Results \\
\hline Kim et al. 2010 (82) & $\begin{array}{l}\text { Effects of HPE on preventing monoiodoacetate } \\
\text { induced osteoarthritis in rats }\end{array}$ & $\begin{array}{l}\text { Dose dependent decrease in glycosaminoglycans. } \\
\text { A reduction in MMP-2 and MMP-9 }\end{array}$ \\
\hline
\end{tabular}

HPE, human placental extract; MMP, matrix metalloproteinase.

through reduction of ROS and induction of cellularantioxidant enzymes. These properties are worth further exploration and maybe useful in chronic disease in tissues marked with low cell content and cell turnover

\section{HPE as a potential therapeutic for $\mathrm{OA}$}

\section{OA: ROS-mediated SIPS}

$\mathrm{OA}$ is a disease characterized by articular cartilage degeneration, subchondral cysts, and synovial inflammatory response (65). Articular cartilage remains the critical target in attenuating OA progression (66). Previous therapies have aimed to stabilize articular cartilage to prevent further damage and degradation. However, growing evidence now suggests innate regenerative potential for articular cartilage that is stymied by ROS induced chondrocyte senescence. As previously stated, an excess amount of ROS causes to considerable DNA damage which elicits cellular growth arrest $(56,67)$. Chondrocytes that withstand the chronic inflammation found in an OA joint will often transition into the irreversible SISP phenotype (56). Potentiating the problem is the proinflammatory state chondrocytes attained once transitioned to the SISP phenotype. These SISPchondrocytes secrete increased levels of IL-1 (68), IL-6, IL-7 (69) and metalloproteases and demonstrate a decreased response to anabolic growth factors (70-77). Stress induced senescence phenotype-chondrocyte may also be implicated in the observed subchondral edema, and osteophyte formation due to high secretion of VEGF $(78,79)$. Furthermore, oxidative stress from increased ROS may contribute to chondrocyte senescence by promoting endoplasmic reticulum (ER) stress (69). ER stress has been shown to down-regulate expression of cartilage matrix proteins and aggrecans and increase chondrocyte apoptosis $(80,81)$.

\section{HPE in OA}

HPE harbors antioxidant properties and may play a significant role in preventing chondrocyte transitioning to SIPS, thereby allowing a favorable environment for in-situ cartilage regeneration. While no study directly assesses HPE's potential in reduction of ROS mediated SIPS, one study exist that demonstrates reduction in cartilage degeneration after use of HPE (see Table 4).

Kim et al. (82) investigated the effect of HPE on cartilage degradation in vitro osteoblastic MG-63 cells, articular cartilage rabbit explants, and in vivo monoiodoacetate (MIA)-induced OA. MMP-2 activity was significantly decreased in a dose dependent manner for HPE-treated MG63 cells when compared to the control (no HPE). Similarly, the authors revealed lower levels of glycosaminoglycans (GAG) release upon rhIL-1alpha stimulated explants when treated HPE. Furthermore, the authors demonstrated reduced severity of MIA-induced OA by radiographic and histopathological examination for rats treated with HPE. They also report in-vivo reduction in MMP-2 and MMP-9 expression in rats treated with HPE. Their study demonstrates the potential of HPE in mitigating OA progression. As such, more studies like these are necessary.

\section{Conclusions}

The human placenta is a temporary organ that contains immunomodulatory, growth stimulatory, and antioxidant properties to facilitate fetal development. These properties have been studied to assess HPE's potential to treat a variety of ailments. OA, which is marked by cartilage damage and degradation, may be one such malady. The regenerative and antioxidant capabilities of HPE may help mitigate the occurrence of SIPS-chondrocytes thereby optimizing in-situ articular cartilage regeneration. More well-designed in-vitro and in-vivo studies are needed to study the role of HPE in OA.

\section{Acknowledgments}

None.

\section{Footnote}

Conflicts of Interest: All authors have completed the ICMJE 
uniform disclosure form (available at http://dx.doi. org/10.21037/atm.2019.10.20). The authors have no conflicts of interest to declare.

Ethical Statement: The authors are accountable for all aspects of the work in ensuring that questions related to the accuracy or integrity of any part of the work are appropriately investigated and resolved.

\section{References}

1. Allen KD, Golightly YM. State of the evidence. Curr Opin Rheumatol 2015;27:276-83.

2. Murphy LB, Cisternas MG, Pasta DJ, et al. Medical Expenditures and Earnings Losses Among US Adults With Arthritis in 2013. Arthritis Care Res (Hoboken) 2018;70:869-76.

3. Dibonaventura $M$ dacosta, Gupta $S, M c D o n a l d ~ M$, et al. Evaluating the health and economic impact of osteoarthritis pain in the workforce: results from the National Health and Wellness Survey. BMC Musculoskelet Disord 2011;12:83.

4. Wang K, Kim HA, Felson DT, et al. Radiographic Knee Osteoarthritis and Knee Pain: Cross-sectional study from Five Different Racial/Ethnic Populations. Sci Rep 2018;8:1364.

5. Sophia Fox AJ, Bedi A, Rodeo SA. The basic science of articular cartilage: structure, composition, and function. Sports Health 2009;1:461-8.

6. Hayflick L, Moorhead PS. The serial cultivation of human diploid cell strains. Exp Cell Res 1961;25:585-621.

7. Hou A, Chen P, Tang H, et al. Cellular senescence in osteoarthritis and anti-aging strategies. Mech Ageing Dev 2018;175:83-7.

8. Jeon OH, Wilson DR, Clement CC, et al. Senescence cell-associated extracellular vesicles serve as osteoarthritis disease and therapeutic markers. JCI Insight 2019. doi: 10.1172/jci.insight.125019.

9. Jeon OH, David N, Campisi J, et al. Senescent cells and osteoarthritis: a painful connection. J Clin Invest 2018;128:1229-37.

10. Houard X, Goldring MB, Berenbaum F. Homeostatic mechanisms in articular cartilage and role of inflammation in osteoarthritis. Curr Rheumatol Rep 2013;15:375.

11. Ng M, Song S, Piuzzi NS, et al. Stem cell industry update: 2012 to 2016 reveals accelerated investment, but market capitalization and earnings lag. Cytotherapy 2017;19:1131-9.
12. Freitag J, Bates D, Boyd R, Set al. Mesenchymal stem cell therapy in the treatment of osteoarthritis: reparative pathways, safety and efficacy - a review. BMC Musculoskelet Disord 2016;17:230.

13. Hussain N, Johal H, Bhandari M. An evidence-based evaluation on the use of platelet rich plasma in orthopedics - a review of the literature. SICOT J 2017;3:57.

14. Chahla J, Cinque ME, Piuzzi NS, et al. A Call for Standardization in Platelet-Rich Plasma Preparation Protocols and Composition Reporting. J Bone Jt Surg 2017;99:1769-79.

15. Schippinger G, Prüller F, Divjak M, et al. Autologous Platelet-Rich Plasma Preparations: Influence of Nonsteroidal Anti-inflammatory Drugs on Platelet Function. Orthop J Sport Med 2015;3:2325967115588896.

16. Cao X, Luo P, Huang J, et al. Intraarticular senescent chondrocytes impair the cartilage regeneration capacity of mesenchymal stem cells. Stem Cell Res Ther 2019;10:86.

17. Pogozhykh O, Prokopyuk V, Figueiredo C, et al. Placenta and Placental Derivatives in Regenerative Therapies: Experimental Studies, History, and Prospects. Stem Cells Int 2018;2018:4837930.

18. McIntyre JA, Jones IA, Danilkovich A, et al. The Placenta: Applications in Orthopaedic Sports Medicine. Am J Sports Med 2018;46:234-47.

19. Medawar PB. Some immunological and endocrinological problems raised by the evolution of viviparity in vertebrates. Symp Soc Exp Biol 1953;7:320-37.

20. Kim MJ, Shin KS, Jeon JH, et al. Human chorionic-platederived mesenchymal stem cells and Wharton's jellyderived mesenchymal stem cells: a comparative analysis of their potential as placenta-derived stem cells. Cell Tissue Res 2011;346:53-64.

21. Choi JH, Jung J, Na KH, et al. Effect of mesenchymal stem cells and extracts derived from the placenta on trophoblast invasion and immune responses. Stem Cells Dev 2014;23:132-45.

22. Selmani Z, Naji A, Zidi I, et al. Human Leukocyte Antigen-G5 Secretion by Human Mesenchymal Stem Cells Is Required to Suppress T Lymphocyte and Natural Killer Function and to Induce CD4 + CD25 high FOXP3 + Regulatory T Cells. Stem Cells 2008;26:212-22.

23. Yang ZX, Han ZB, Ji YR, et al. CD106 identifies a subpopulation of mesenchymal stem cells with unique immunomodulatory properties. Vergani A, editor. PLoS One 2013;8:e59354.

24. Abumaree MH, Abomaray FM, Alshabibi MA, et al. Immunomodulatory properties of human placental 
mesenchymal stem/stromal cells. Placenta 2017;59:87-95.

25. Muñoz-Fernández R, Prados A, Leno-Durán E, et al. Human decidual stromal cells secrete $\mathrm{C}-\mathrm{X}-\mathrm{C}$ motif chemokine 13, express B cell-activating factor and rescue B lymphocytes from apoptosis: distinctive characteristics of follicular dendritic cells. Hum Reprod 2012;27:2775-84.

26. Abumaree $\mathrm{MH}$, Al Jumah MA, Kalionis B, et al. Human placental mesenchymal stem cells (pMSCs) play a role as immune suppressive cells by shifting macrophage differentiation from inflammatory M1 to anti-inflammatory M2 macrophages. Stem Cell Rev 2013;9:620-41.

27. Magatti M, De Munari S, Vertua E, et al. Amniotic Mesenchymal Tissue Cells Inhibit Dendritic Cell Differentiation of Peripheral Blood and Amnion Resident Monocytes. Cell Transplant 2009;18:899-914.

28. Khalifeh Soltani S, Forogh B, Ahmadbeigi N, et al. Safety and efficacy of allogenic placental mesenchymal stem cells for treating knee osteoarthritis: a pilot study. Cytotherapy 2019;21:54-63.

29. Leverson JD, Phillips DC, Mitten MJ, et al. Exploiting selective BCL-2 family inhibitors to dissect cell survival dependencies and define improved strategies for cancer therapy. Sci Transl Med 2015;7:279ra40.

30. Endrinaldi E, Darwin E, Zubir N, et al. The Effect of Mesenchymal Stem Cell Wharton's Jelly on Matrix Metalloproteinase-1 and Interleukin-4 Levels in Osteoarthritis Rat Model. Open Access Maced J Med Sci 2019;7:529-35.

31. Beacock M. Does eating placenta offer postpartum health benefits? Br J Midwifery 2012;20:464-9.

32. Pan SY, Chan MK, Wong MB, et al. Placental therapy: An insight to their biological and therapeutic properties. J Med Therap 2017. doi: 10.15761/JMT.1000118.

33. Biswas TK, Auddy B, Bhattacharya NP, et al. Wound healing activity of human placental extracts in rats. Acta Pharmacol Sin 2001;22:1113-6.

34. Selander J, Cantor A, Young SM, et al. Human Maternal Placentophagy: A Survey of Self-Reported Motivations and Experiences Associated with Placenta Consumption. Ecol Food Nutr 2013;52:93-115.

35. Noh TK, Chung BY, Kim SY, et al. Novel AntiMelanogenesis Properties of Polydeoxyribonucleotide, a Popular Wound Healing Booster. Int J Mol Sci 2016;17:1448.

36. Donnelly L, Campling G. Functions of the placenta. Anaesth Intensive Care Med 2016;17:349-53.

37. Tonello G, Daglio M, Zaccarelli N, et al. Characterization and quantitation of the active polynucleotide fraction
(PDRN) from human placenta, a tissue repair stimulating agent. J Pharm Biomed Anal 1996;14:1555-60.

38. Sini P, Denti A, Cattarini G, et al. Effect of polydeoxyribonucleotides on human fibroblasts in primary culture. Cell Biochem Funct 1999;17:107-14.

39. Nair B, Elmore AR; Cosmetic Ingredient Review Expert panel. Final report on the safety assessment of human placental protein, hydrolyzed human placental protein, human placental enzymes, human placental lipids, human umbilical extract, placental protein, hydrolyzed placental protein, placental enzymes, placental lipids, and umbilical extract. Int J Toxicol 2002;21 Suppl 1:81-91.

40. Philipps AF, Holzman IR, Teng C, et al. Tissue concentrations of free amino acids in term human placentas. Am J Obstet Gynecol 1978;131:881-7.

41. Lupo MP, Cole AL. Cosmeceutical peptides. Dermatol Ther 2007;20:343-9.

42. Marraccini ME, Gorman KS. Exploring Placentophagy in Humans: Problems and Recommendations. J Midwifery Womens Health 2015;60:371-9.

43. Choi JS, Kim JD, Yoon HS, et al. Full-thickness skin wound healing using human placenta-derived extracellular matrix containing bioactive molecules. Tissue Eng Part A 2013;19:329-39.

44. Cukrová V, Hrkal Z. Purification and characterization of granulocyte-macrophage colony stimulating factor from human placenta. J Chromatogr 1987;413:242-6.

45. Horibe N, Okamoto T, Itakura A, et al. Levels of hepatocyte growth factor in maternal serum and amniotic fluid. Am J Obstet Gynecol 1995;173:937-42.

46. Uzumaki H, Okabe T, Sasaki N, et al. Identification and characterization of receptors for granulocyte colonystimulating factor on human placenta and trophoblastic cells. Proc Natl Acad Sci U S A 1989;86:9323-6.

47. Parida R, Das S, Raju TR, et al. Human placental extract ameliorates cytokine and cytokine receptor signaling in the rat hippocampus upon Benzo[a]Pyrene exposure. J Chem Neuroanat 2019;98:8-16.

48. Yamauchi A, Kamiyoshi A, Koyama T, et al. Placental extract ameliorates non-alcoholic steatohepatitis (NASH) by exerting protective effects on endothelial cells. Heliyon 2017;3:e00416.

49. Samiei F, Jamshidzadeh A, Noorafshan A, et al. Human Placental Extract Ameliorates Structural Lung Changes Iinduced by Amiodarone in Rats. Iran J Pharm Res IJPR 2016;15:75-82.

50. Zahno A, Brecht K, Morand R, et al. The role of CYP3A4 in amiodarone-associated toxicity on HepG2 cells. 
Biochem Pharmacol 2011;81:432-41.

51. Jung J, Lee HJ, Lee JM, et al. Placenta extract promote liver regeneration in CCl4-injured liver rat model. Int Immunopharmacol 2011;11:976-84.

52. Kwon TR, Oh CT, Choi EJ, et al. Human placental extract exerts hair growth-promoting effects through the GSK-3 $\beta$ signaling pathway in human dermal papilla cells. Int J Mol Med 2015;36:1088-96.

53. Hong JW, Lee WJ, Hahn SB, et al. The Effect of Human Placenta Extract in a Wound Healing Model. Ann Plast Surg 2010;65:96-100.

54. Ben-Porath I, Weinberg RA. The signals and pathways activating cellular senescence. Int J Biochem Cell Biol 2005;37:961-76.

55. Musumeci G, Szychlinska MA, Mobasheri A. Age-related degeneration of articular cartilage in the pathogenesis of osteoarthritis: molecular markers of senescent chondrocytes. Histol Histopathol 2015;30:1-12.

56. Dai SM, Shan ZZ, Nakamura H, et al. Catabolic stress induces features of chondrocyte senescence through overexpression of caveolin 1: possible involvement of caveolin 1-induced down-regulation of articular chondrocytes in the pathogenesis of osteoarthritis. Arthritis Rheum 2006;54:818-31.

57. Zorov DB, Juhaszova M, Sollott SJ. Mitochondrial reactive oxygen species (ROS) and ROS-induced ROS release. Physiol Rev 2014;94:909-50.

58. Chance B, Sies H, Boveris A. Hydroperoxide metabolism in mammalian organs. Physiol Rev 1979;59:527-605.

59. Couto N, Wood J, Barber J. The role of glutathione reductase and related enzymes on cellular redox homoeostasis network. Free Radic Biol Med 2016;95:27-42.

60. Yang HT, Yang MC, Sun JJ, et al. Catalase eliminates reactive oxygen species and influences the intestinal microbiota of shrimp. Fish Shellfish Immunol 2015;47:63-73.

61. Miao L, St Clair DK. Regulation of superoxide dismutase genes: Implications in disease. Free Radic Biol Med 2009;47:344-56.

62. Lee TH, Park DS, Jang JY, et al. Human Placenta Hydrolysate Promotes Liver Regeneration via Activation of the Cytokine/Growth Factor-Mediated Pathway and Anti-oxidative Effect. Biol Pharm Bull 2019;42:607-16.

63. Bak DH, Na J, Choi MJ, et al. Anti-apoptotic effects of human placental hydrolysate against hepatocyte toxicity in vivo and in vitro. Int J Mol Med 2018;42:2569-83.

64. Bak D, Na J, Im SI, et al. Antioxidant effect of human placenta hydrolysate against oxidative stress on muscle atrophy. J Cell Physiol 2019;234:1643-58.

65. Delanois RE, Etcheson JI, Sodhi N, et al. Biologic Therapies for the Treatment of Knee Osteoarthritis. J Arthroplasty 2019;34:801-13.

66. Qin R, Sun J, Wu J, et al. Pyrroloquinoline quinone prevents knee osteoarthritis by inhibiting oxidative stress and chondrocyte senescence. Am J Transl Res 2019;11:1460-72.

67. Salama R, Sadaie M, Hoare M, et al. Cellular senescence and its effector programs. Genes Dev 2014;28:99-114.

68. Forsyth CB, Cole A, Murphy G, et al. Increased matrix metalloproteinase-13 production with aging by human articular chondrocytes in response to catabolic stimuli. J Gerontol A Biol Sci Med Sci 2005;60:1118-24.

69. Loeser RF. Aging and osteoarthritis: the role of chondrocyte senescence and aging changes in the cartilage matrix. Osteoarthritis Cartilage 2009;17:971-9.

70. Guerne PA, Blanco F, Kaelin A, et al. Growth factor responsiveness of human articular chondrocytes in aging and development. Arthritis Rheum 1995;38:960-8.

71. Martin JA, Ellerbroek SM, Buckwalter JA. Age-related decline in chondrocyte response to insulin-like growth factor-I: The role of growth factor binding proteins. J Orthop Res 1997;15:491-8.

72. Loeser RF, Shanker G, Carlson CS, et al. Reduction in the chondrocyte response to insulin-like growth factor 1 in aging and osteoarthritis: Studies in a non-human primate model of naturally occurring disease. Arthritis Rheum 2000;43:2110-20.

73. Messai H, Duchossoy Y, Khatib AM, et al. Articular chondrocytes from aging rats respond poorly to insulinlike growth factor-1: an altered signaling pathway. Mech Ageing Dev 2000;115:21-37.

74. Scharstuhl A, van Beuningen HM, Vitters EL, et al. Loss of transforming growth factor counteraction on interleukin 1 mediated effects in cartilage of old mice. Ann Rheum Dis 2002;61:1095-8.

75. Iqbal J, Dudhia J, Bird JL, et al. Age-related effects of TGFbeta on proteoglycan synthesis in equine articular cartilage. Biochem Biophys Res Commun 2000;274:467-71.

76. Bobacz K, Gruber R, Soleiman A, et al. Expression of bone morphogenetic protein 6 in healthy and osteoarthritic human articular chondrocytes and stimulation of matrix synthesis in vitro. Arthritis Rheum 2003;48:2501-8.

77. Tran-Khanh N, Hoemann CD, McKee MD, et al. Aged bovine chondrocytes display a diminished capacity to produce a collagen-rich, mechanically functional cartilage 
extracellular matrix. J Orthop Res 2005;23:1354-62.

78. Lingaraj K, Poh CK, Wang W. Vascular endothelial growth factor (VEGF) is expressed during articular cartilage growth and re-expressed in osteoarthritis. Ann Acad Med Singapore 2010;39:399-403.

79. Hashimoto S, Creighton-Achermann L, Takahashi K, et al. Development and regulation of osteophyte formation during experimental osteoarthritis. Osteoarthritis Cartilage 2002;10:180-7.

80. Yang L, Carlson SG, McBurney D, et al. Multiple signals induce endoplasmic reticulum stress in both primary

Cite this article as: Gwam C, Ohanele C, Hamby J, Chughtai N, Mufti Z, Ma X. Human placental extract: a potential therapeutic in treating osteoarthritis. Ann Transl Med 2019. doi: $10.21037 / \mathrm{atm} .2019 .10 .20$ and immortalized chondrocytes resulting in loss of differentiation, impaired cell growth, and apoptosis. J Biol Chem 2005;280:31156-65.

81. Yang L, McBurney D, Tang SC, et al. A novel role for Bcl-2 associated-athanogene-1 (Bag-1) in regulation of the endoplasmic reticulum stress response in mammalian chondrocytes. J Cell Biochem 2007;102:786-800.

82. Kim J, Kim T, Park S, et al. Protective effects of human placenta extract on cartilage degradation in experimental osteoarthritis. Biol Pharm Bull 2010;33:1004-10. 